1. Um pouco de história;

2. O problema propriamente dito; 3. Conclusão.

Edgar Fraga Moreira Filho Wilson Pereira *

Economista pela Pontifícia Universidade Católica de Campinas, com intensivo em administração de empresas pela mesma universidade e vários outros cursos de aperfeiçoamento.

* * Economista pela Pontifícia Universidade Católica de Campinas, com vários cursos intensivos e extensivos na área de marketing; professor de matemática aplicada e estatística metodológica na Faculdade de Ciências Econômicas, Contábeis e Administrativas da PUCC.

\section{UM POUCO DE HISTÓRIA}

A crise do petróleo provocada pelos países árabes produtores, que teve seu apogeu em fins de 1973, ocasionou ao Brasil, além das já sabidas conseqüências em sua economia (aumento da divida externa, desequilíbrio da balança comercial, evasão de dívidas, recrudescimento da inflação, queda no desenvolvimento econômico, etc.,) uma retração no comércio de autopeças.

Tentaremos demonstrar nesse nosso ensaio, como a contenção de gasolina está afetando esse ramo de atividade.

O preço médio anual CIF, em US\$/barril de petróleo bruto e nafta importados pelo Brasil de 73-76 teve a seguinte evolução:

Tabela 1

\begin{tabular}{l|c|c}
\hline Ano & US\$ $^{1}$ & Crescimento \% \\
\hline 1973 & 3,8175 & - \\
1974 & 12,5675 & 229,5 \\
1975 & 12,3158 & $(-2,0)$ \\
$1976^{*}$ & 12,8600 & 4,4 \\
\hline
\end{tabular}

1 Conjuntura Econômica.

* Media jan./nov.

Como conseqüência, o preço médio anual da gasolina comum, que vinha sofrendo aumentos compatíveis com outros bens, teve alta abrupta a partir de 74, conforme mostrado na tabela 2 .

Tabela 2

\begin{tabular}{l|c|c|c}
\hline Ano & $\begin{array}{c}\text { Preco médio } \\
(\text { Cr } \$ / 1)^{*}\end{array}$ & $\begin{array}{c}\text { Crescimento } \\
(\% \text { anual })\end{array}$ & Indice \\
\hline 1968 & 0,2882 & - & 100,0 \\
1969 & 0,3840 & 33,2 & 133,2 \\
1970 & 0,4911 & 27,9 & 170,4 \\
1971 & 0,5659 & 15,2 & 196,3 \\
1972 & 0,6921 & 22,3 & 240,1 \\
1973 & 0,7960 & 15,0 & 276,2 \\
1974 & 1,6733 & 110,2 & 580,5 \\
1975 & 2,4683 & 47,5 & 856,4 \\
1976 & 4,0166 & 62,7 & $1,393,7$ \\
\hline
\end{tabular}

* Na cidade de São Paulo.

Nota: Com a adoçấo da politica de aumento de preços, a partir de 74 , a evolução do consumo foi alterada, camo demonstra a tabela 3 .

Com a adoção da política de aumento de preços, a partir de 74, a evolução do consumo foi alterada, como demonstra a tabela 3. 
Tabela 3

\begin{tabular}{l|c|c|c}
\hline Ano & $\begin{array}{c}\text { Consumo } \\
\text { total de } \\
\text { gasolina * }\end{array}$ & $\begin{array}{c}\text { Crescimento } \\
\text { (\% anual) }\end{array}$ & indice \\
\hline 1968 & $8.219,0$ & - & 100,0 \\
1969 & $8.747,0$ & 6,4 & 106,4 \\
1970 & $9.704,8$ & 11,0 & 118.1 \\
1971 & $10.617,7$ & 9,4 & 129,2 \\
1972 & $11.937,5$ & 12,4 & 145,3 \\
1973 & $14.009,0$ & 17,4 & 170,5 \\
1974 & $14.521,2$ & 3,7 & 176,7 \\
1975 & $14.608,9$ & 0,6 & 177,8 \\
1976 & $14.646,0$ & 0,3 & 178,2 \\
\hline
\end{tabular}

* Em milhóes de litros.

Fontes: Anuderio Estatistico do IBGE Conjuntura Economica.

Pode-se notar, na tabela 3, que a política de aumento de preço, como medida de contenção de consumo, vem surtindo os efeitos esperados.

A proibição de funcionamento dos postos de gasolina à noite e nos fins de semana, dificuldades para estacionamento nos centros das grandes cidades, etc., além da ameaça de racionamento, têm contribuído no sentido de desestimular o uso do automóvel.

Importante é notar que, apesar da queda no ritmo de crescimento do consumo total de gasolina, a frota de veículos movidos por esse combustível continua a se expandir a taxas altamente significativas.

Dessa forma, podemos deduzir que o consumo específico (litros/veículo) vem-se reduzindo de uma maneira bem mais acentuada, e é o que mostramos na tabela 4.
Como se pode notar, a taxa de crescimento anual da frota de veículos a gasolina, que vinha se intensificando até 74 , diminuiu seu ritmo a partir de 75, mantendo-se, entretanto, em nível que podemos considerar alto.

Por outro lado, o consumo médio por veículo que já era declinante, caiu substancialmente a partir de 74, época em que se adotou a política de aumento de preço da gasolina, como medida de contenção do consumo.

- A que atribuir a redução no consumo específico da gasolina, que já existia antes da adoção ' da política de aumento de preço?

- Estaria havendo um melhor disciplinamento no uso da gasolina?

- Os nossos veículos estariam se tornando mais econômicos?

- Estaria havendo uma redução na $\mathrm{km} / \mathrm{ano}$ ?

E possivel que esteja havendo um melhor aproveitamento no uso da gasolina, através da melhoria das estradas, redução de velocidade e outras de igual teor, cujos parâmetros são difíceis de serem medidos.

Uma análise do perfil da frota, na tabela 5, mostra-nos o comportamento da média de cilindros/veículo no período 68-76.

Verificanıos aqui um crescimento menos que proporcional da frota em cilindros relativamente à frota em números absolutos, havendo, como conseqüência, uma redução na média do número de cilindros por veículo, do ano de 68 para o ano de 76 de 14,5\% (veja gráfico 1 ).

Tabela 4

\begin{tabular}{|c|c|c|c|c|c|c|}
\hline Anos & $\begin{array}{l}\text { Frota/veíc. } \\
\text { a gasolina } \\
\text { (unidades)' }\end{array}$ & $\begin{array}{l}\text { Crescimento } \\
(\% \text { anual) }\end{array}$ & lindice & $\begin{array}{l}\text { Cons./gasolina } \\
\text { p/veículo } \\
\text { (litro) }\end{array}$ & $\begin{array}{c}\text { Crescimento } \\
\text { (\% anual) }\end{array}$ & Indice \\
\hline 1968 & 1.800 .000 & - & 100,0 & 4.566 & - & 100,0 \\
\hline 1969 & 2.035 .500 & 13,1 & 113,1 & 4.297 & $(-5,9)$ & 94,1 \\
\hline 1970 & 2.319 .100 & 13,9 & 128,8 & 4.185 & $(-2,6)$ & 91,7 \\
\hline 1971 & 2.689.000 & 16,0 & 149,4 & 3.948 & $(-5,7)$ & 86,5 \\
\hline 1972 & 3.128 .800 & 16,4 & 173,8 & 3.815 & $(-3,4)$ & 83.5 \\
\hline 1973 & 3.660 .600 & 17,0 & 203,4 & 3.827 & 0,3 & 83,8 \\
\hline 1974 & 4.296 .000 & 17.4 & 238,7 & 3.380 & $(-11,7)$ & 74,0 \\
\hline 1975 & 4.910 .900 & 14,3 & 272,8 & 2.975 & $(12,0)$ & 65,2 \\
\hline 1976 & 5.482 .000 & 11,6 & 304,5 & 2.672 & $(\ldots 10,2)$ & 58,5 \\
\hline
\end{tabular}

' Arquivo particular: a frota foi calculada com base na produção. 
Tabela 5

\begin{tabular}{|c|c|c|c|c|c|c|}
\hline Ano & $\begin{array}{l}\text { Frota em } \\
\text { cilindros }\end{array}$ & $\begin{array}{c}\text { Crescimento } \\
\text { (\% anual) }\end{array}$ & Indice & $\begin{array}{l}\text { Média de } \\
\text { cil./veículo }\end{array}$ & $\begin{array}{c}\text { Crescimento } \\
\text { (\% anual) }\end{array}$ & Índice \\
\hline 1968 & 9.545 .800 & - & 100,0 & 5,30 & - & 100,0 \\
\hline 1969 & 10.556 .200 & 10,6 & 110,6 & 5,19 & $(-2,1)$ & 97,9 \\
\hline 1970 & 11.688 .000 & 10,7 & 122,7 & 5,04 & $(-2,9)$ & 95,1 \\
\hline 1971 & 13.322 .400 & 14,0 & 139,6 & 4,95 & $(-1,8)$ & 93,4 \\
\hline 1972 & 15.255 .800 & 14,5 & 159,8 & 4,88 & $(-1,4)$ & 92,1 \\
\hline 1973 & 17.256 .300 & 15,0 & 183,8 & 4,71 & $(-3,5)$ & 88,9 \\
\hline 1974 & 20.007 .300 & 15,9 & 213,0 & 4,66 & $(-1,1)$ & 87,9 \\
\hline 1975 & 22.592 .900 & 12,9 & 240,5 & 4,60 & $(-1,3)$ & 86,8 \\
\hline 1976 & 24.830 .000 & 9,9 & 264,3 & 4,53 & $(-1,5)$ & 85,5 \\
\hline
\end{tabular}

Verificamos aqui um crescimento menos que proporcional da frota em cilindros relativamente à frota em números abolutos, havendo, como conseqüéncia, uma reduçáo na média do número de cilindros por veículo, do ano de 68 para o ano de 76 de $14,5 \%$ (veja.gráfico 1 ).

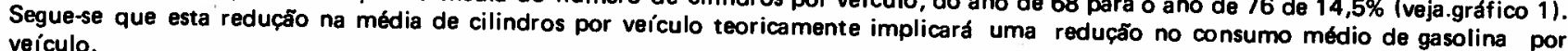

Gráfico 1

Evolução da média de cilindros por veículo à gasolina 76/80.

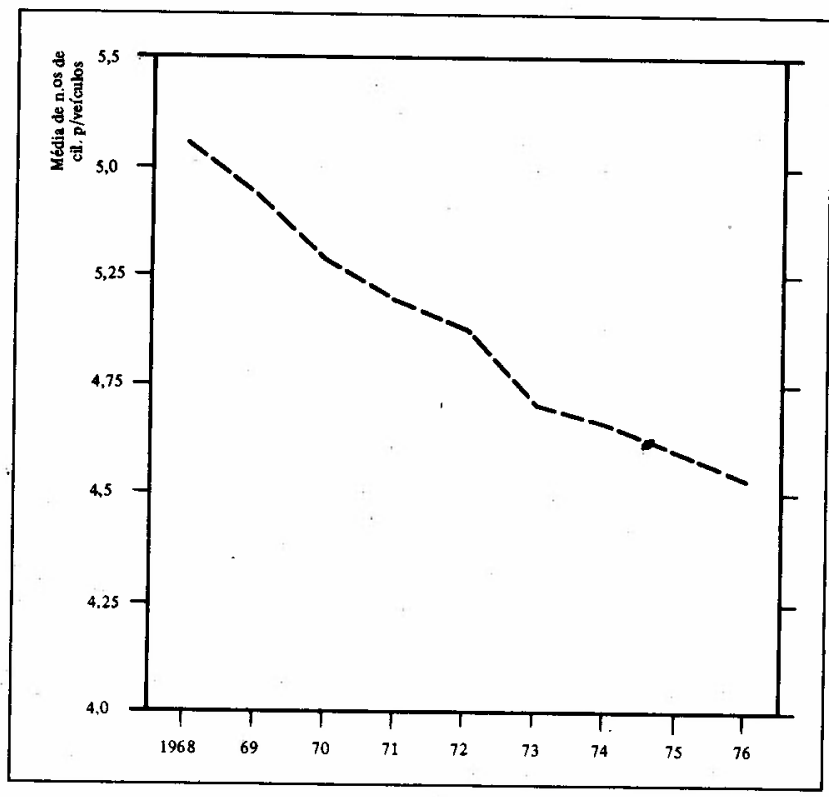

Segue-se que esta redução na média de cilindros por veículo teoricamente implicará numa redução no consumo médio de gasolina por veículo.

Dessa forma, acreditamos que a redução no consumo por veículo, anterior à política de aumento de preços se justifica pelos motivos acima expostos.

A intensificação na redução do consumo, a partir de 1974, motivada pelos constantes aumentos de preço, somente se justifica pela redução na quilometragem média anual dos veículos.

Este fato, como veremos, influi diretamente sobre a atividade da indústria de autopeças.

\section{O PROBLEMA PROPRIAMENTE DITO}

Admitindo-se que a causa principal da redução de consumo deve-se à redução da quilometragem média anual, temos que admitir, forçosamente, que toda autopeça de desgaste demandaria um prazo maior para sua substituição, uma vez que a menor quilometragem implicaria em maiores intervalos de troca, ocasionando, dessa forma, uma retração na demanda de autopeças de reposição.

\section{Como justificar essa assertiva?}

De imediato necessitamos saber qual a correlação existente entre preço da gasolina e seu consumo específico (por veículo).

Se apenas nos baseássemos nos aumentos nominais do preço, sem deflacioná-los, estaríamos incorrendo em erro de distorção analítico. Assim, utilizamos como deflator do preço da gasolina, o indice geral de preços - disponibilidade interna, coluna 2 da Conjuntura Econômica da FGV.

A tabela 6 retrata no período de 68-76 um aumento real de preço da ordem de $156 \%$, e que este vinha-se mantendo em níveis razóaveis até 73, havendo em 74 um crescimento abrupto de $63,4 \%$ para em 75 e 76 manter-se no nível de $15 \%$.

Depurada essa variável, tratamento semelhante precisamos dar à outra, ou seja, o consumo médio por veículo.

Conforme enfocado anteriormente, a redução do consumo também deveu-se a um melhor disciplinamento de seu uso (pouco significativo) e, principalmente pela mudança do perfil da frota. Desta forma, precisamos eliminar seus efeitos, conforme a tabela 7. 
Tabela 6

\begin{tabular}{l|c|c|c|c|c|c}
\hline Anos & $\begin{array}{c}\text { Preco medio } \\
\text { p/litro/Cr\$ * }\end{array}$ & $\begin{array}{c}\text { Crescimento } \\
\text { (\% anual) }\end{array}$ & $\begin{array}{c}\text { indice } \\
\text { preco } \\
\text { nominal }\end{array}$ & $\begin{array}{c}\text { Preco médio } \\
\text { p/litro/Cr\$ } \\
\text { deflacionado** }\end{array}$ & $\begin{array}{c}\text { Crescimento } \\
\text { (\% anual). }\end{array}$ & $\begin{array}{c}\text { indice } \\
\text { preço } \\
\text { deflacionado }\end{array}$ \\
\hline 1968 & 0,2882 & - & 100,0 & 0,1812 & - & 100,0 \\
1969 & 0,3840 & 33,2 & 133,2 & 0,2000 & 10,4 & 110,4 \\
1970 & 0,4911 & 27,9 & 170,4 & 0,2135 & 6,8 & 117,8 \\
1971 & 0,5659 & 15,2 & 196,3 & 0,2042 & $1-4,4)$ & 112,7 \\
1972 & 0,6921 & 22,3 & 240,1 & 0,2136 & 4,6 & 117,9 \\
1973 & 0,7960 & 15,0 & 276,2 & 0,2134 & $(-0,1)$ & 117,8 \\
1974 & 1,6733 & 110,2 & 580,5 & 0,3486 & 63,4 & 192,4 \\
1975 & 2,4683 & 47,5 & 856,3 & 0,4026 & 15,5 & 222,2 \\
1976 & 4,0166 & 62,7 & $1,393,7$ & 0,4638 & 15,2 & 256,0 \\
\hline
\end{tabular}

* Na cidade de São Paulo.

** Deflator: Indice Geral de Preços - Disponibilidade Interna - col. 2 - base: 65-67 = 100 - Conjuntura Económica.

Tabela 7

\begin{tabular}{l|c|c|c}
\hline Anos & $\begin{array}{c}\text { indice } \\
\text { cons./veic. } \\
\text { (A) }\end{array}$ & $\begin{array}{c}\text { indice } \\
\text { cil./veic. } \\
\text { (B) }\end{array}$ & $\begin{array}{c}\text { indice cons. } \\
\text { deflacionado } \\
\text { (A/B X 100) }\end{array}$ \\
\hline 1968 & 100,0 & 100,0 & 100,0 \\
1969 & 94,1 & 97,9 & 96,1 \\
1970 & 91,7 & 95,1 & 96,4 \\
1971 & 86,5 & 93,4 & 92,6 \\
1972 & 83,6 & 92,1 & 90,8 \\
1973 & 83,8 & 88,9 & 94,3 \\
1974 & 74,0 & 87,9 & 84,2 \\
1975 & 65,2 & 86,8 & 75,1 \\
1976 & 58,5 & 85,5 & 68,4 \\
\hline
\end{tabular}

De posse das variáveis índice de consumo/ veículo e índice de preço/gasolina/litro deflacionados, respectivamente, pelo indice de cilindros por veículo e índice de preço - disponibilidade interna, podemos, finalmente, equacionar os efeitos no consumo, motivados por um aumento real no preço.

Para tanto, através de uma análise de regressão, tentaremos encontrar uma fórmula matemática que explique o relacionamento entre as nossas variáveis.

A especificação linear considerada foi:

$\hat{\mathbf{g}}=\mathbf{a}+\mathbf{b p}$, em que:

$\hat{\mathbf{g}}=$ consumo estimado da gasolina,

$\mathbf{a}=$ elemento autônomo

$\mathbf{b}=$ coeficiente angular $\mathbf{e}$

p $=$ preço.

A estimativa pelo método dos mínimos quadrados resultou em: $\hat{g}=115,6-0,18 p$, com um poder de explicação $\left(R^{2}\right)$ da ordem de $95,4 \%$ e um valor de $t_{p}$ de student $=12,0739$ evidencian- do, ao nivel de confiança de $95 \%$ de probabilidade, a existência de correlação entre as variáveis em estudo.

O teste para verificação de autocorrelação nos resíduos (Durbin-Watson) resultou em $\mathbf{d}=$ 1,60 , indicando a não existência de correlação serial.

\section{CONCLUSĀO}

Os resultados mostram que a diminuição do consumo médio de gasolina por veículo provocará uma diminuição na quilometragem média rodada.

Sabendo-se que o desgaste de uma peça é função direta da quilometragem/ano rodada do veículo, seu desgaste será tanto menor quanto for esta quilometragem. Em conseqüência, a reposição de autopeças será feita com maiores intervalos, ocasionando queda na demanda global do produto.

Admitindo-se, por exemplo, que o preço/litro da gasolina atinja, até o final de 77, o valor de $\mathrm{Cr} \$ 8,20$, com aumentos intermediários em julho e outubro de $16,7 \%$ e $17,1 \%$ respectivamente sobre o preço de abril (cr $\$ 6,00)$ na cidade de São Paulo, teremos até o final de 77 um preço médio ponderado da ordem de $\mathrm{Cr} \$ 6,55 /$ litro. Desta forma, confrontando este preço com o do ano anterior, teremos um aumento percentual (média sobre média) da ordem de $64,6 \%$. Admitindo-se ainda que o índice de preço (disponibilidade interna) em 77 sofra um acréscimo de $45 \%$ sobre 76 , teremos um aumento real de preço/litro de gasolina, estimado em 13,5\% até o final de 77 .

Aceitas estas hipóteses, nosso índice de preço (deflacionado) que era de 256,0 em 76 (veja tabela 6), passa, após este aumento, a 290,56 que, aplicado em nossa equação, nos dará o novo ín- 
Gráfico 2

Curva de consumo de gasolina em função do preço real.

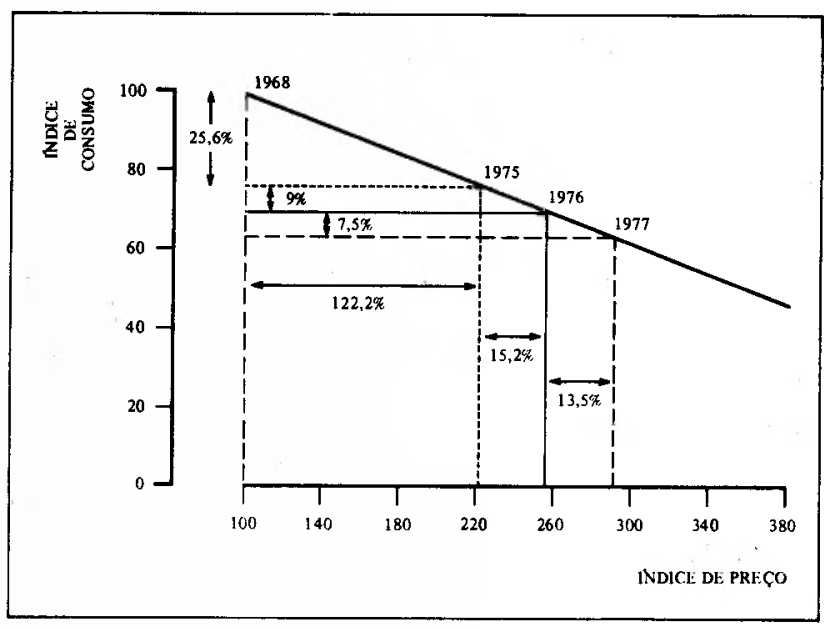

dice de consumo $(63,3)$. Este, confrontado com o anterior $(68,4)$, (veja tabela 7 ), evidenciará uma redução no consumo específico da gasolina de $7,5 \%$.

Destarte, se a frota de veículos movidos a gasolina sofrer em 1977 um acréscimo de 9,8\%

\section{Gráfico 3}

Economia da gasolina-conseqüência na demanda de autopeças.

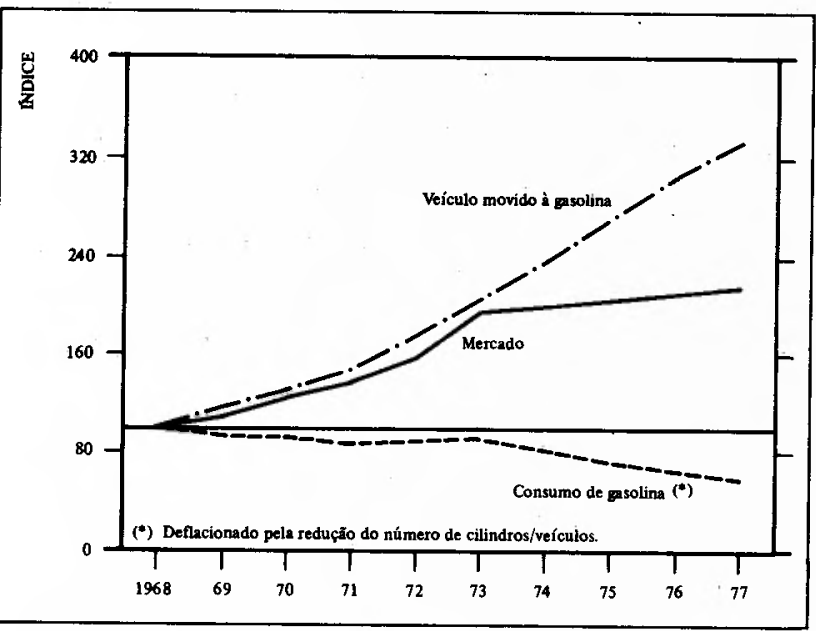

sobre 76, concluiremos que a demanda de autopeças para veículos aliméntados a gasolina teria um crescimento líquido de apenas 1,6 no decorrer de 77 , conforme ilustração no gráfico 3 , justificando, desta feita, aquilo que nos propusemos no início deste ensaio.

NÃO IMPORTA ONDE VOCÊ ESTEJA NOSSAS PUBLICAÇÕES CHEGAM ATÉ VOCÊ.

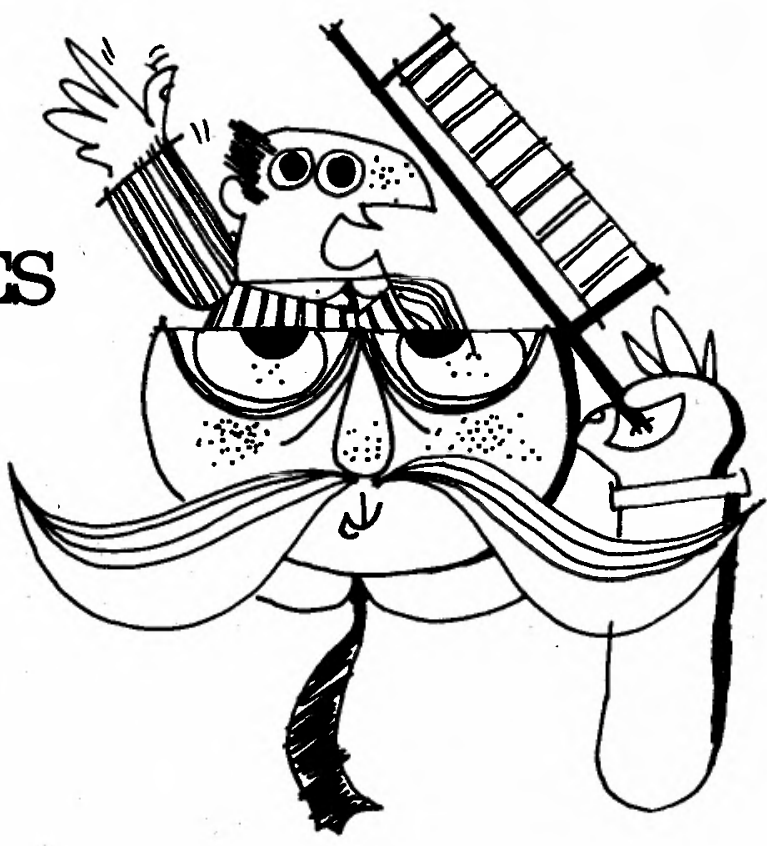

